Munther N Kazanje

BDS, MSc (Assist Prof)

Saad Y INoori

BDS, MSc (Assisst Lect)

\section{Measurement of the Palatal Depth for}

\section{Completely Edentulous Patient.}

\author{
Dept of Prosthetic Dentistry
}

College of Dentistry, University of Mosul

\begin{abstract}
Aim: To measure the depth of the palate for completely edentulous patients and relate this parameter to the type of reflection of the soft palate. Materials and methods: Fixed reference point was determined in the hard palate of a hundred upper edentulous casts made by pouring impressions of completely edentulous patients attending the prosthodontic clinic in College of Dentistry, University of Mosul. This reference point was determined by drawing two lines, the first line from the center of incisive papilla to the fovea palatinae, and the second line crossing the first line exactly in its middle. The crossing point of these two lines was considered the point of measurement. A depth measuring digital vernia (Lezaco art, 2406 China) measuring to the nearest of $0.01 \mathrm{~mm}$ recorded the measurement. The curvature of soft palate was determined by measuring the angle formed by the highest point of the palate and a point one centimeter posterior to fovea palatinae. Results: The results showed that $65 \%$ of the measurements of the palatal depth fall in the moderate category of palatal depth and $79 \%$ of soft palate reflections were of gradual type. Conclusion: There is an acceptable success rate of complete denture could be achieved in cases of moderate palatal depth with gradual reflection of soft palate.

Keyword: Palatal depth, Complete denture, Soft palate.
\end{abstract}

Kazanje MN, INoori SY. Measurement of the Palatal Depth for Completely Edentulous Patient. AlRafidain Dent J. 2008; 8(1 ):23 -25 .

Received: 5/12/2006

Sent to Referees: $7 / 12 / 2006$

Accepted for Publication: 23/4/2007

\section{INTRODUCTION}

Success of the complete denture is the most important project in prosthodontics. From numbers of local factors that affect prognosis of complete denture is the depth of palate ${ }^{(1)}$, and it's posterior extension ${ }^{(2)}$.

The depth of the palate can affect to a great extent the stability and retention of maxillary denture ${ }^{(2-6)}$. So the configuration of the maxillary ridge and palate appears to affect the adaptation of a denture base (7). The soft palate affects the extension of posterior palatal seal of the upper complete denture ${ }^{(2,8-10)}$.

The aim of this study is to measure the different types of palatal depth and relate these measurements to the types of soft palate.

\section{MATERIALS AND METHODS}

A total of 100 master upper casts obtained from casting impressions of edentulous ridges of completely edentulous male and female patients attending prosthetic dental clinic in College of Dentistry
University of Mosul.

The period of edentulousness for these patients ranged from 6 months -2 years.

A dental surveyor was used to determine zero tilt of the casts during measurements. For determining the fixed points in the palate, two lines crossing each other were drawn on the cast, the first line extended from the middle of incisive papilla to the fovea palatine, while the second line crossed the first one in its middle. The crossing point was fixed on the palate by a sharp needle and marked by lead pencil.

The depth of the palate in this point was measured by adjusting a digital depth measuring vernier perpendicular to the plane touching the upper ridge and the needle of the verniaer allowed to touch the predetermined point in the palate, Figure (1).

The data were recorded and categoryized according to the depth of the palate into three categories deep (15.5-20.0 mm), moderate $(10.5-15 \mathrm{~mm})$, and shallow palate $(5.5-10 \mathrm{~mm})$. The type of soft palate reflection in relation to hard palate was also evaluated by measuring the angle formed 
by the highest point of the palate (point A) posterior to fovea palatinae, Figure (2), and lowest point on the soft palate $1 \mathrm{~cm}$

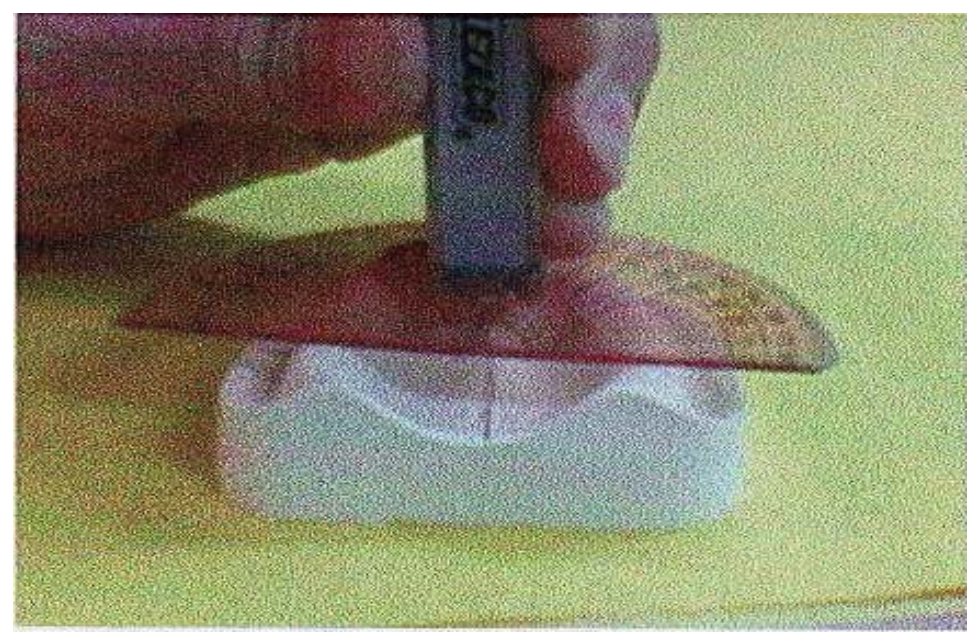

Figure (2): Measurement of Soft Palate, Indication.

The angle was categorized into flat reflection (more than $150^{\circ}$ ), moderate reflection (more than $130^{\circ}$ ) and sharp reflection (less than $\left.130^{\circ}\right)^{(2)}$.

\section{RESULTS}

The distribution of age of the sample was presented in Table (1). Analysis of variance was performed with Duncan mul- tiple range tests. The results revealed a statistically significant difference between the three categories of palatal depth present, Table (2).

Table (3) showed the Duncan multiple range test for the mean palatal depth. The percentage of soft palate reflection in relation to the depth of hard palate was calculated and presented in Table (4).

Table (1): The distribution of age of the sample

\begin{tabular}{cccc}
\hline Age & male & female & total \\
\hline $\mathbf{5 0 - 5 5}$ & 25 & 14 & 39 \\
$\mathbf{5 6 - 6 0}$ & 28 & 12 & 40 \\
$\mathbf{6 1 - 6 8}$ & 12 & 9 & 21 \\
\hline
\end{tabular}

Table (2) Analysis of variance (ANOVA) of three palatal depth

\begin{tabular}{cccccc}
\hline Source of variance & DF & Sum of square & Mean square & F- value & P-value \\
\hline Palatal depth & 2 & 569.68 & 284.84 & 165.44 & 0.000 \\
Error & 97 & 167.01 & 1.72 & & \\
Corrected total & 99 & 736.69 & & & \\
\hline
\end{tabular}

Df: degree of freedom.

Table (3) Duncan s multiple range test for the mean palatal depth

\begin{tabular}{ccccc}
\hline Palatal depth & Number & Mean & \pm SD & Duncan group \\
\hline Deep & 21 & 8.8101 & 1.178 & $\mathrm{~A}$ \\
Moderate & 65 & 12.7691 & 1.378 & $\mathrm{~B}$ \\
Shallow & 14 & 16.964 & 1.168 & $\mathrm{C}$ \\
\hline
\end{tabular}

Means with different letters are significantly different; Sd: Standard deviation; F value $=165.44 ;$ Significant at $P \leq 0.001$ 
Table (4) percentage of soft palate reflection in relation to depth of hard palate.

\begin{tabular}{ccccc}
\hline \multirow{2}{*}{ Palate depth } & \multirow{2}{*}{ Number of casts } & \multicolumn{3}{c}{ Soft palate reflection } \\
\cline { 3 - 5 } & & sharp & gradual & flat \\
\hline Deep & 21 & $17(89 \%)$ & $4(11 \%)$ & \\
Moderate & 65 & $4(6.15 \%)$ & $50(79 \%)$ & $11(16.9)$ \\
Shallow & 14 & & $4(29 \%)$ & $10(71 \%)$ \\
\hline
\end{tabular}

\section{DISCUSSION}

The study showed that $21 \%$ of the edentulous patients examined had deep palate. This type of palatal morphology may affect the adaptation of upper denture due to dimensional changes during processing, which result in poor stability ${ }^{(1,10)}, 17$ patient from this type of palate depth had a sharp reflection of soft palate which will promote poor extension posteriority and result in poor retention ${ }^{(6-8)}$.

The high percentage $(79 \%)$ of gradual reflection of soft palate was associated with moderate depth of hard palate, which may have better extension and better relation.

\section{CONCLUSION}

One could conclude that there is an acceptable success rate regarding retention and stability of upper complete denture, and could be achieved in cases of moderate depth Palate with gradual reflection of soft palate.

\section{REFERENCES}

1.Jacobson TE, Knoll AS. A contemporary review of the factors involved in completes denture part I: Retention. J Prosthet Dent. 1983; 49: 5-15.

2.Heart Well CM, Ran AO. Syllabus of
Complete Denture $.2^{\text {nd }}$ ed. LEA and FEBIGER Philadelphia. 1975; P: 4.

3.Jacobson TE, Knoll AS. A contemporary review of the factors involved in completes denture part II: Stability. J Prosthet Dent. 1983; 49: 165-172.

4.Jacobson TE, Knoll AS. A contemporary review of the factors involved in completes denture. Part III: Support. J Prosthet Dent. 1983; 49: 314-320.

5.Engelmeier R, Phoinex R. Patient evaluation and treatment planning for complete denture therapy. Dent clin North America. $1986 ; 140$.

6. Colon A, Kotawal K, Manmgelsdorff A. Analysis of posterior palatal seal and the palatal form as related to the retention of complete denture. J Prosthct Dent. 1982; 47:

7.Glazier S, Firtell D, Haiman L. Posterior peripheral seal distortion related to height of the maxillary ridge. $J$ Prosthet Dent. 1980; 43.

8. Millsap $\mathrm{CH}$. The posterior palatal seal area for complete denture. Dent clin North America.1969; 663.

9. Silverman SI. Dimensional and displacement patterns of posterior palatal seal. J Prosthet Dent. 1971; 25: 470.

10. Nagle, Sears. Denture Prosthesis. $2^{\text {nd }}$ ed. CV Mosby Co. St.Louis 1962; Pp: 92-93. 